\title{
Revenue Management and Dynamic Pricing Practices at the Gateway Hotel, Chennai
}

\author{
S. Hemalatha and S.P. Deepeka
}

\begin{abstract}
Revenue management is extensively utilized by the hotel industry to decide on room allocation and tariff. Hotel revenue management is a scientific method that also increases the profitability of the hotel business. Hotels uses revenue management to replenish inventory, to predict demand and to set the price of the product. The Revenue Management structure are also deployed by airline industries, hotel industries, electric utilities etc. The concept of "Price Multipliers" is based on concession which varies in seasonal indicated price. Nowadays, this "Price Multipliers" concept is adapted by Dynamic Pricing in the industry. The price multipliers has its impact from occupancy till arrival. In this study the authors', highlights on various room packages offered at The Gateway Hotel IT Expressway, Chennai and its effect on hotel revenue management. The proposed approach is based on utilizing "Seasonal Packages" and to maximize the revenue, the demand-price sensitivity and also taking in to account on current demand of the guest.
\end{abstract}

Keywords--- Revenue Management, Dynamic Pricing, Price Multipliers

\section{INTRODUCTION}

A Hotel or an inn is defined by the British Law as a "place where a Bonafide traveler can receive food and shelter, provided he is in a position to pay for it and is in a fit condition to be received". Hotel operations vary from the size they operate, the way they function, and price they fix for each services offered by them. The classification of hotels set a wide standard for the industry which has been adopted by most of the hotels and by major hospitality companies. The following are the general categories of hotels;

- Full service

- Upscale luxury

- Economy and limited service

- Historic inns and boutique hotels

- Focused or select service

- Timeshare and destination clubs

- Extended stay

Taj group by Indian Hotels Company Limited (IHCL), is a chain of hotels and resorts which has its headquarters at Oxford House, Mumbai. Jamsetji Tata is the founder of the group who incorporated the chain in 1903. Taj Group operates 108 hotels across India and 17 hotels in the USA, UK, Middle

S. Hemalatha, Asst. Professor (SG), Course Coordinator, MBA Hospitality Management, School of Management, Hindustan University, Chennai

S.P. Deepeka, Teaching Research Associate, School of Management, Hindustan University, Chennai

DOI: 10.9756/BIJIEMS.8142
East, Maldives, Africa, Sri Lanka, Malaysia and Bhutan. Taj Group is known for its excellence and constant effort to achieve world-class standards in all aspects of operations. The hotel is operated under the category of luxury, premium, midmarket and value segments of the market through the following brands:

- Taj: A luxury full-service hotels, resorts and palaces

- Taj Exotica: Concept of resort and spa

- Taj Safaris: Offers wildlife lodges

- Vivanta by Taj: Upper Upscale Hotels

- The Gateway Hotel: Upscale or mid-market full serviced hotels and resorts

- Ginger: Economy hotels

\section{The Gateway Hotels \& Resorts, Chennai}

The Gateway Hotels and Resorts are full serviced upscale hotels and resorts operated in South Asia, by offering quick, crisp and consistent service for travelers looking for hasslefree and contemporary experiences. The hotels provides services under 8 Zones - Enter, Stay, Hangout, Meet, Work, Workout, Unwind and Explore. The services provide for 24/7 are breakfast, Workout studio and laundry. They are intended to provide guests round the clock Fitness through services like 'Active Foods' and 'In-room Yoga'. Currently the Gateway has 40 operating and signed up hotels across the country. They have also planned to increase the property to at least 50 over the upcoming years.

\section{Business Model}

Tata companies makes use of Tata Business Excellence Model (TBEM), which extent from strategy \& leadership, safety \& climate change. TBEM uplifts improvements through a system of benchmarking and assessment which has been adapted from the model of Malcolm Baldrige.

Many international hotels and chains overlook on 'affordable chic'. With challenging lifestyles, young generations of India wanted to do things in its environment at its own pace. This gave rise to the concept of fitness, flexibility and freedom by the Gateway hotel.

- Fitness: In-room yoga, active foods, extended swimming pool hours and $24 \times 7$ fitness centres

- Flexibility: $24 \times 7$ services of breakfast, room service, laundry and business-related activities - which differs from an upscale brand

- Freedom: The guests were given their freedom to draw their own holiday itinerary through the concept of 'Gateway explore'. Gateway coffee and wines are their signature dishes. 
Operational level study was done to create a quality product experience. The Hotel has its highlights on independent identity, positioning the brand 'Gateway' with expectations and attributes of the brand. The hotel experience has been classified and segregated in to zones, which is an interesting approach when compared to the other brands. The Gateway as an independent Brand, still operates under the Taj brand and also follows the methods followed by the Taj Brand in terms of reservation centre and their loyalty programme known as Taj Inner Circle. This brand is fully supported by the Taj network, using the sales and marketing team, small call centres and the Public Relations network.

\section{SIGNIFICANCE OF THE STUDY}

Dynamic pricing is utilized by most of the industries like airlines, hotels and retailing. A Product delivered to a customer should satisfy their need, wants and requirements. It will be reflected through the customer's readiness to pay, and it will also be profitable for the hotel as well. This study concentrate on the pricing strategies adopted by The Gateway Hotel offered. It contributes on the optimization of revenue through the room packages. This research helps to comprehend the various methods deployed by The Gateway Hotel to persuade on their Dynamic Pricing

\section{OBJECTIVES}

- To study the concept of revenue management in the hotel industry with special reference to The Gateway hotels

- To comprehend the revenue management process involved in promoting the rooms.

- To highlight the various room packages offered in The Gateway hotel.

- To assess the different market segments of The Gateway hotel.

\section{METHODOLOGY}

For this study, The Gateway Hotel IT ExpresswayChennai has been identified. Since the study is conversed about dynamic pricing qualitative methodology is adopted. Observation methodology is being used to find out the strategies used to fix the price during high demand and low demand season. The Primary sources for this study are Sales Heads and Revenue manager of The Gateway Hotel IT expressway, Chennai. The other details of the hotel have been taken from their respective websites which gives more inputs on their pricing and packages available to the customers.

\section{LIMITATIONS}

- This study is limited to The Gateway Hotel IT Expressway, Chennai only.

- Company documents are not provided since it is confidential in nature.

- Busy schedules in the organization environment limited the observing factor.

\section{REVIEW OF LITERATURE}

- Kimes\&Wirtz (2003) has defined Revenue management as "the application of information systems and pricing strategies to allocate the right capacity to the right customer at the right price at the right time. This puts revenue management practice into the realm of marketing management where it plays a key role in demand creation and managing consumer behaviour".

- Neil Salerno (2006) in an article titled "Hotel Revenue Management is Now More Important than ever" stated that an increase demand in occupancy will decrease the room availability which is said to be the supply. This will also leads to choose higher rates since lower rates will not be available. Nowadays hotels has to face day to day Operational expenses in order to face them, business is required. A good Occupancy ratio or ARR cannot be produced by often selling at the same rate for all the available rooms.

- Yuri Levin, Jeff McGill, Mikhail Nediak (2008) in a research paper " Risk in Revenue management and Dynamic pricing" has developed a new model for dynamic pricing of consumable services or products it also incorporates a risk measure which allows a probability control on total revenues that falls below a minimum fitting level. The assumption of the prescribed formulation is within a restricted time period, sales must occur and there is a finite set of already given prices, followed by a demand of pricedependent, non-homogeneous Poisson process.

- Neil Salerno (2007) in a Journal of Hotel marketing Coach titled "Managing Hotel Revenue and everything that drives it five considerations worth repeating" stated that, When there is low sale demand, the hotel can be positioned by concentrating on valueadded marketing within the given marketplace. The Hotel has to be positioned in the same way as earlier which indicates its location, facilities and amenities. The concept of Revenue management is based on the ability to foresee the future demand on occupancy and making decisions accordingly.

\section{IMPORTANCE OF DYNAMIC PRICING}

Product development, Promotion, Market Research and other tasks are the activities which is mostly given preference by the Marketing. Apart from the above mentioned activities, Pricing decision is also an important activity given the maximum importance as it is directly related to Revenue of the organization. The following are some of the significance of Dynamic Pricing in an Organization

- Most Flexible Marketing Mix Variable: Price is considered to be the most adjustable criteria among all marketing decisions. Product and Distribution activity related decisions requires a huge period to change or at times it may stay constant since it is time consuming;whereas, Pricing decision changes rapidly. The flexibility pricing decisions is considerable when there is a stimulation in the demand for pricing 
decisions triggered by the competitors. He may also fix lower price for a prospective customer during a telephonic exchange on demand. A marketer who is in charge of online operations can also increase the prices on fast moving products with the help of technology (websites).

- Setting the Right Price: Loss of Revenue to an Organization is mainly because of hastily made decisions on Pricing without proper research and strategic evaluation. Low set prices leads to an understanding that the company lacks in additional profits which can be earned due to the willingness of spending more by the target market. Prices set far above the ground affects the revenue as it prevents potential customers from purchasing the item. Right level Price requires knowledge on current market especially with different pricing levels implemented during New product testing.

- Trigger of First Impressions: Customer's perceives a product as soon as they understand the price at first sight of the product. While the end decision to purchase a product relies on the value offered by the whole marketing activity. Price of the product evaluated by the customer can also be based on its price. It can also be based on the understanding of the Product. Triggering the first impression of the product reflects on the purchasing decision.

- Important Part of Sales Promotion: Sales Promotions are part of adjustments in Price. Setting up of Lower price at initial stage of product introduction develops interest towards that particular product. But, it should avoid adjusting the prices frequently. Since continuous increasing and decreasing price levels can lead customers to look forward to price reductions and it can also hold back the purchase decision until the price reduction occurs over.

\section{FACTORS AFFecting PRICING DeCISION}

The Price fixation for a product can be influenced by many factors which can be summarized into two main groups:

- Internal Factors: Price decisions should be made based on various factors which should indicate company's decision and measures. If required, the factors can also be changed or altered to a large extent. Making a change often is not advisable and it cannot be realistic even if the company has control over the factors. Manufacturing ability like how much it can be produced over a period of time should be reflected on Pricing decision. Production increase will decrease the cost of each item produced and thus it automatically leads the marketer to lower cost of the product. But productivity increase might demand major changes in the facility of manufacturing which is actually time consuming and it will not reduce the price of the products for a significant period of time.

- External Factors: There are integers of influencing factors which are not restricted by the company but it will be reflected in its pricing decisions. By
Understanding these factors, it is required for the marketer to carry out research to examine what is happening in each market in which the company serves. This will have an effect on the factors which will contrast by market.

\section{Steps in the Price Setting Process}

The essential steps that has to be followed for setting up of effective Price setting. These steps are mandatory as it ascertains the price among direct and indirect customers. They are:

1. Observing the objectives of the Company and its Marketing initiatives

2. Setting up of Initial Cost

3. Establishing Standard Price

4. Promotional Strategy for Pricing

5. Establishing Ownership and Options for Payment

\section{RESUltS AND DisCUSSION}

- Revenue management concept is used in the hotel to predict the demand and to protect the inventory for sales at a higher price for Rooms and food and Beverage.

- Dynamic pricing allows separate optimization of the prices for early bird registering consumers, who normally pay a lower price when compared to the purchasers who pay a premium for convenience.

- The Seasonal packages offered by The Gateway Hotel IT Expressway Chennai, is influenced by various factors like target customers, seasonality, competitors and demand.

- Business Package, Executive and Suite saver Package will be applicable for all the room categories on special conditions.

- The Gateway Hotel IT Expressway Chennai has a great impact on revenue because of extended stay package which, boosts the revenue of the hotel due to adapting price multiplier strategy

- Apart from the special offers the hotel also offers special discount on spa and gym which attract walk in guests.

- The sources of channels for getting business is through Global Distribution System (GDS), Taj Reservation Worldwide (TRW), and Online Travel Agents (OTA).

- The Prominent location of the hotel gives business to them from major companies in the IT Corridor Chennai.

- The advertising tools used by the hotel are the Sales team, Brochure, Hoardings and the hotel Website. They rarely go for media advertising.

- It is observed that by using dynamic pricing the hotel can set different strategies to fix their room tariffs particularly during off season.

- With the help of revenue management process during the demand period, the hotel can restrict or close discounts to generate more revenue by segregating the 
market for differential rates and by utilizing Rate For Proposal (RFP) with the airlines.

\section{ConClusion}

The Revenue management is done to maximize the revenue by controlling the prices offered with limited amount of supply. The benefits given by dynamic pricing can be segregated into three categories

- increase in ARR (Average Room Revenue)

- increase in sales quantity and

- collection of data based on buyer behavior

In order to be successful in dynamic pricing strategy, vigilant planning has to be established by preparing the organization for setting the targets and choosing appropriate resources. This study thoroughly analyses various packages offered by The Gateway Hotel IT Express way, Chennai to attract the customers and to increase the hotel revenue. Each packages offered by the hotel is attracting different customer segmentation and helps to analyze on the overall revenue obtained in the particular season. Overall the study highlights on the room packages and revenue management practices in The Gateway Hotel IT Express way, Chennai. The result of this research provides important effects for dynamic pricing on revenue management and thus helps to understand to fix the price during the particular season.

\section{ACKNOWLEDGEMENT}

The authors are grateful to the Sales Manager and Assistant Revenue Manager - The Gateway Hotel, for their support to conduct this study and for giving information and inputs on Revenue Management and Dynamic Pricing Practices carried at The Gateway Hotel, Chennai.

\section{REFERENCE}

[1] Gabriel Bitran, "An Overview of Pricing Models for Revenue Management ", Stern School of Business, New York University, December 2002

[2] Guillermo Gallyo, "A Multiproduct Dynamic Pricing Problem and its Application to Network Yield Management", Columbia University, October 1993

[3] Mohammed Saleh, " Dynamic Pricing of Hotel Revenue Management", Cairo University, 2009.

[4] Omar Besbes, " Dynamic Pricing Strategies in the Process of Demand Shocks", Columbia University, November 2013. 